\title{
Early stroke case-fatality rates in three hospital registries in the Northeast and Southeast of Brazil
}

\author{
Taxas de letalidade precoce por acidente vascular cerebral em três registros \\ hospitalares no nordeste e sudeste do Brasil
}

Tiótrefis G. Fernandes ${ }^{1,7}$, Alessandra C. Goulart2,3, Tania F. Campos4, Neide M. G. Lucena Karen L. A. Freitas ${ }^{5}$, Cláudia M. Trevisan', Isabela M. Benseñor ${ }^{2,7}$, Paulo A. Lotufo ${ }^{2,7}$

\begin{abstract}
Few studies have addressed early cerebrovascular lethality in Brazil. Objective: To evaluate 10 and 28-day stroke case-fatality rates in three hospitals in three Brazilian cities. Methods: We described the stroke registries in São Paulo, João Pessoa, and Natal. Results: Out of a total of 962 first-ever events (mean age, 68.1 years-old; 53\% men), 83.6\% (804 cases) were classified as ischemic and 16.4\% (158) as hemorrhagic stroke. Overall, the case-fatality rates and $95 \%$ confidence intervals $(95 \% \mathrm{Cl})$ for hemorrhagic stroke events were higher than for ischemic events, both at $10(12.3 \%$; 95\% Cl 7.2-17.4 versus 7.0\%;95\% Cl 5.3-8.8) and at 28 days (19.8\%;95\% $\mathrm{Cl} 13.6-26.0$ versus 11.1\%;95\% Cl 8.9-13.3). Conclusions: We did not find any substantial differences in early case-fatality rates according to stroke subtypes, when comparing the three centers.
\end{abstract}

Key words: stroke, lethality, hemorrhagic stroke, ischemic stroke.

\section{RESUMO}

Poucos estudos abordaram a letalidade cerebrovascular precoce no Brasil. Objetivo: Avaliar taxas de letalidade por acidente vascular cerebral (AVC) em 10 e 28 dias após evento em três hospitais em três cidades brasileiras. Métodos: Foram descritos os registros de AVC em São Paulo, João Pessoa e Natal. Resultados: De um total de 962 primeiros eventos (idade média de 68,1 anos; 53\% homens), 83,6\% (804 casos) foram classificados como AVC isquêmico e 16,4\% (158) como hemorrágico. As taxas de letalidade e intervalos de confiança de 95\% (IC95\%) para eventos de AVC hemorrágico foram maiores que para os isquêmicos em: 10 (12,3\%; IC95\% 7,2-17,4 versus 7,0\%; IC95\% 5,3-8,8) e 28 dias (19,8\%; IC95\% 13,6-26,0 versus 11,1\%; IC95\% 8,9-13,3). Conclusões: Não foram encontradas diferenças substanciais nas taxas de letalidade precoce por subtipo de AVC ao comparar os três centros estudados.

Palavras-Chave: acidente vascular cerebral, letalidade, acidente vascular hemorrágico, acidente vascular cerebral isquêmico.

Despite declining stroke mortality over recent years, Brazil has one of the highest stroke mortality rates in the Americas for both genders, with a higher proportion of deaths among the poorest states in the country ${ }^{1-3}$. To explain the higher burden of cerebrovascular deaths, it is important to ascertain both the incidence and case-fatality rates among Brazilian macroregions. Two Brazilian populationbased studies estimated the incidence and case-fatality rates for first-ever stroke in the cities of Joinville, Santa Catarina State $^{4}$, and Matão, São Paulo State ${ }^{5}$. In Matão, incidence rates per 100,000 inhabitants for ischemic stroke and intracerebral hemorrhage of 91.9 and 14.7, respectively, were reported. The

\footnotetext{
${ }^{1}$ Instituto de Saúde e Biotecnologia, Universidade Federal do Amazonas (UFAM), Coari AM, Brazil;

${ }^{2}$ Hospital Universitário, Universidade de São Paulo (USP), São Paulo SP, Brazil;

${ }^{3}$ Hospital das Clínicas, USP, São Paulo SP, Brazil;

${ }^{4}$ Departamento de Fisioterapia, Universidade Federal do Rio Grande do Norte (UFRN), Natal RN, Brazil;

5Universidade Federal da Paraíba (UFPB), João Pessoa PB, Brazil;

6Universidade Federal de Santa Maria (UFSM), Santa Maria RS, Brazil;

${ }^{7}$ Faculdade de Medicina, USP, São Paulo SP, Brazil.

Correspondence: Tiótrefis G. Fernandes; Center of Clinical Research, 3rd floor, Hospital Universitário, University of São Paulo; Avenida Professor Lineu Prestes 2.565; 05508-000 São Paulo SP - Brazil; E-mail: tfernandes@hu.usp.br

Support: The PRODIAVC study was supported by the Conselho Nacional de Desenvolvimento Científico e Tecnológico (CNPq) - 409797/2006-5. The EMMA study was funded by the CNPq and Fundação de Amparo à Pesquisa do Estado de São Paulo (FAPESP).

Conflict of interest: There is no conflict of interest to declare.

Received 15 February 2012; Received in final form 15 August 2012; Accepted 22 August 2012
} 
30-day case-fatality rate was $18.5 \%$ and the one-year case-fatality rate was $30.9 \%^{5}$. In the study carried out in Joinville, the 30-day case-fatality for all stroke subtypes was $19.1 \%{ }^{4}$.

In our previous hospital-based registry analysis (April 2006 to December 2008) performed in the city of São Paulo ${ }^{6}$, we found stroke subtype proportions ( $84.9 \%$ ischemic stroke, $15.1 \%$ intracerebral hemorrhage) that were similar to those in the studies performed in Matão and Joinville. Our results were also similar to other hospital-based registries in the Northeastern region of Brazil, in the cities of Natal, Rio Grande do Norte ${ }^{7}$, and Fortaleza, Ceará ${ }^{8}$. However, the overall stroke 30-day case-fatality rate was lower (12.8\%, first-ever and recurrent) than in Matão (18.5\%), Joinville (19.1\%) and Fortaleza (20.9\%), and similar to that in Natal (10.4\%)

Our aim was to investigate regional differences in 10 and 28-day stroke case-fatality rates by comparing data from two public hospitals located in the Northeastern region and one in the Southeastern region of Brazil, based on the standardized World Health Organization (WHO) stepwise approach to stroke surveillance?.

\section{METHODS}

\section{Design and population study}

The study subjects were the participants in two registries of stroke: in São Paulo, the EMMA study (Stroke Mortality and Morbidity Study); and in Natal/João Pessoa, the PRODIAVC (Diagnosis and Intervention Program in Stroke). The first of these is an ongoing prospective stroke cohort at the University Hospital of the University of São Paulo (HUUSP). Details of the EMMA cohort have been previously described elsewhere ${ }^{10}$. The second of these is a study involving the Monsenhor Walfredo Gurgel Hospital (HMWG) in Natal, and the Senador Humberto Lucena Emergency and Trauma Hospital (HETSHL) in João Pessoa, in the states of Rio Grande do Norte and Paraíba, respectively. All of these hospitals are public services that are free on demand.

HU-USP is a community-based teaching hospital (260 beds) in Butantã (São Paulo), a neighborhood on the west side of the city with 424,377 inhabitants (2009). This hospital provides the sole support for emergencies coming from primary care units and for paramedic ambulances in the area. Neurological referrals from this community facility are made to Hospital das Clínicas, a tertiary-care hospital located $8 \mathrm{~km}$ away.

HMWG is the main tertiary-care public hospital in the city of Natal. It is also a teaching hospital with 264 beds. HETSHL is a reference center for orthopedic and neurological trauma in the city of João Pessoa and has 187 beds. Among the three hospitals, this is the only one with neurosurgery service. There is no stroke unit in any of these hospitals, but all of them have intensive care units that admit stroke patients.

We gathered data on individuals over the age of 35 years with a first-ever stroke. They all had a medically confirmed diagnosis of ischemic stroke or intracerebral hemorrhage and were admitted during the following periods: from April 2006 to December 2010 in São Paulo; from January 2009 to December 2009 in Natal; and from May 2009 to October 2010 in João Pessoa.

\section{Data gathering}

The data gathering for this study was based on the WHO manual of steps for stroke surveillance, hospital phase (step 1) ${ }^{9}$. The baseline information included sociodemographic data such as age, gender, race (according to self-reported skin color, i.e., white, mixed or black), years of education (none or less than year, 1-7 years and 8 or more years), along with the patients' history of stroke and preexisting comorbidities, such as high blood pressure and diabetes. All the data gathered were based on self-reported information from patients or caregivers, or came from the hospital records. Furthermore, acute stroke characteristics (stroke subtype and date, and time of initial symptoms) and information on acute hospital care (delayed hospitalization and length of hospital stay) were also evaluated by trained interviewers. Vital status during follow-up (at 10 and 28 days) was updated for all participants by means of telephone interviews, medical registries, and death certificates provided by local health statistics departments.

The written informed consent was obtained from all potential stroke patients admitted to the hospitals who agreed to participate in each study center. The research protocols had previously been approved by the institutional review boards of all the centers.

\section{Definition of stroke}

Stroke was defined in accordance with the WHO criteria as "rapidly developing symptoms and/or signs of focal (or at times global) neurological alterations, and lasting longer than 24 hours (or leading to death), and of presumed vascular origin”. This definition excluded transient ischemic attack and recurrent stroke. Each event was classified as being the patient's first-ever-in-a-lifetime clinically evident stroke, and it was confirmed through noncontrast computed tomography (CT) findings and a neurological evaluation during hospitalization. The stroke diagnosis was validated by physicians, who classified stroke subtypes based on the International Classification of Diseases $10^{\text {th }}$ revision as ischemic stroke (ICD-10: I-63) or intracerebral hemorrhage (ICD10: I-61). Because there were only a few cases of subarachnoid hemorrhage, these cases were not included in this analysis.

\section{Statistical analysis}

Categorical and continuous variables were compared according to the study center, using the $\chi^{2}$ test and ANOVA, respectively. Age was analyzed as a continuous variable or according to age strata (35-59 years-old, 60-79 years-old 
and $\geq 80$ years-old). Age standardization was applied to the 10 and 28-day case-fatality rates using the sampling distribution of São Paulo as the default, by means of the direct method. No adjustments for sex were made, because there were no differences regarding sex distribution among the centers. Stratified analyses according to the main stroke subtypes (ischemic and hemorrhagic) were performed among the study centers. Age-adjusted logistic regression was performed to estimate the risks of death (odds ratio - OR) at 10 and 28 days, according to sociodemographic and cardiovascular factors for ischemic and hemorrhagic stroke, separately. All the tests were two-tailed, and a p-value $<0.05$ was considered significant with 95\% confidence intervals (95\%CI). The Statistical Package for the Social Sciences (SPSS) software, version 16.0, was used for the statistical analyses.

\section{RESULTS}

The total number of participants with stroke who fulfilled the inclusion criteria at baseline in the three sites was 962 . The mean age at baseline was 68.1 years (standard deviation \pm 13.8 ) and $52.3 \%$ of the participants were men, independently of the originating center. Approximately $58 \%$ of the participants were white and $30 \%$, illiterate. The highest percentages of black people and individuals with no education were reported in the city of João Pessoa, followed by Natal and then São Paulo (Table 1).

\section{Previous disease}

Most of the patients had a history of previous high blood pressure. Other preclinical conditions presented included diabetes and heart disease, accounting for approximately one quarter of the total, with no differences among the cities. Out of the 962 individuals classified as first-ever stroke cases, $98.6 \%$ had their diagnosis confirmed by CT scan and the other $1.4 \%$ had their diagnoses of stroke and stroke subtype confirmed only through clinical criteria, stated by a neurologist after a complete clinical and neurological evaluation (Table 1).

\section{Case-fatality and risk factors associated}

Table 2 shows the 10- and 28-day age-standardized casefatality rates for total and main stroke subtypes according to the study center. Overall, hemorrhagic stroke death rates were higher than ischemic ones both at 10 and 28 days. Other than advanced age, the risk factors for ischemic stroke casefatality at 28 days were diabetes (OR=1.69; 95\%CI 1.06-2.68) and previous heart disease $(\mathrm{OR}=1.86$; 95\%CI 1.17-2.96) after adjustment for age. No other risk factors had a statistically significant influence on early stroke case-fatality rates according to the stroke subtype (data not shown).

Table 1. Baseline characteristics of stroke patients according to location of the study.

\begin{tabular}{|c|c|c|c|c|c|}
\hline Characteristics & $\begin{array}{c}\text { João Pessoa } \\
\quad(n=45)\end{array}$ & $\begin{array}{c}\text { Natal } \\
(n=288)\end{array}$ & $\begin{array}{l}\text { São Paulo } \\
(n=629)\end{array}$ & $\begin{array}{c}\text { Total } \\
(n=962)\end{array}$ & $p$-value* \\
\hline Mean age - years $( \pm S D)$ & $70.1(12.1)$ & $67.3(15.1)$ & $68.3(13.2)$ & $68.1(13.8)$ & 0.357 \\
\hline \multicolumn{6}{|l|}{ Age strata (\%) } \\
\hline$\leq 59$ & $10(22.2)$ & $87(30.2)$ & $168(26.7)$ & $265(27.5)$ & \multirow{3}{*}{0.514} \\
\hline $60-79$ & $25(55.6)$ & $130(45.1)$ & $318(50.6)$ & $473(49.2)$ & \\
\hline$>80$ & $10(22.2)$ & $71(24.7)$ & $143(22.7)$ & 224 (23.3) & \\
\hline \multicolumn{5}{|l|}{$\operatorname{Sex}(\%)$} & \multirow{2}{*}{0.157} \\
\hline Male & $25(55.6)$ & $137(47.6)$ & $341(54.2)$ & $503(52.3)$ & \\
\hline \multicolumn{6}{|l|}{ Race } \\
\hline White & $17(38.6)$ & $119(41.3)$ & $414(67.0)$ & $550(57.9)$ & \multirow{3}{*}{$<0.001$} \\
\hline Mixed & $17(38.6)$ & $140(48.6)$ & $172(27.8)$ & $329(34.6)$ & \\
\hline Black & $10(22.8)$ & $29(10.1)$ & $32(5.2)$ & $71(7.5)$ & \\
\hline \multicolumn{6}{|l|}{ Years of education (\%) } \\
\hline None & $26(57.8)$ & $125(43.4)$ & $127(20.6)$ & 278 (29.3) & \multirow{3}{*}{$<0.001$} \\
\hline $1-7$ years & $13(28.9)$ & $81(28.1)$ & $290(47.0)$ & $384(40.4)$ & \\
\hline 8 or more years & $6(13.3)$ & $82(28.5)$ & $200(32.4)$ & $288(30.3)$ & \\
\hline \multicolumn{6}{|l|}{ Self-reported pre-stroke conditions (\%) } \\
\hline High blood pressure & $35(77.8)$ & 240 (83.3) & $503(80.0)$ & $778(80.7)$ & 0.419 \\
\hline Diabetes & $12(26.7)$ & $94(32.6)$ & $171(27.2)$ & $277(28.8)$ & 0.227 \\
\hline Heart disease & $10(22.2)$ & $66(22.9)$ & $154(24.5)$ & $230(23.9)$ & 0.844 \\
\hline Stroke diagnosis confirmed by brain CT (\%) & $45(100.0)$ & $287(99.7)$ & $617(98.1)$ & $949(98.6)$ & 0.199 \\
\hline \multicolumn{6}{|l|}{ Stroke subtype (\%) } \\
\hline Ischemic & $33(73.3)$ & $247(85.8)$ & $524(83.3)$ & 804 (83.6) & \multirow[t]{2}{*}{0.107} \\
\hline Intracerebral hemorrhage & $12(26.7)$ & $41(14.2)$ & $105(16.7)$ & $158(16.4)$ & \\
\hline
\end{tabular}

${ }^{*} \mathrm{p}$-values were obtained from ANOVA for continuous variables and $\chi^{2}$ for categorical ones. Some proportions might not add up to $100 \%$ because of rounding. CT: computed tomography; SD: standard deviation. 


\section{DISCUSSION}

We found no differences in age-adjusted early case-fatality rates according to stroke subtype among the three study centers. Through analyzing stroke case-fatality according to stroke subtypes, we found that hemorrhagic stroke mortality rates were higher than ischemic ones at 10 and 28 days in almost all places, except for João Pessoa. The proportions of stroke subtypes observed in our study were quite similar to those reported in a systematic review (1970 to 2008), which was conducted in population-based studies including European countries and the USA ${ }^{11}$.

According to this review, the prevalence rates for cerebral infarction were around 67.8 to $80.5 \%$ and for intracerebral hemorrhage, 6.5 to $19.6 \%$. Early case-fatality rates for all strokes ranged from 17 to $30 \%$ for high-income countries and from 18 to $35 \%$ for low to middle-income countries during the period of 2000 to $2008^{11}$. Similar to our findings, higher proportions of ischemic than of hemorrhagic stroke events were reported from the two-population stroke registries in the cities of Joinville and Matão. However, their 30-day fatality rate estimates for all strokes were higher than those in our study (19.1 and $18.5 \%$ versus $12.5 \%)^{4,5}$. Moreover, the 30-day case-fatality rates for hemorrhagic stroke were much higher than our findings ( 41.4 and $45 \%$ versus $19.8 \%)^{4,5}$. These differences observed might be explained by the exclusion of hemorrhagic cases of greater severity with death before hospital admission, and by the age adjustment that was done in the case-fatality analysis of this study.

Two hospital-based studies in the Northeastern region estimated their case-fatality rates including recurrent cases, for all stroke types. In the study performed in Natal, a similar 30day case-fatality rate for all stroke types of $10.4 \%$ was reported ${ }^{7}$. Another prospective survey conducted among stroke patients admitted to 19 hospitals in the city of Fortaleza estimated an in-hospital mortality rate of $20.9 \%^{8}$. Although some of our findings are similar to the registries from the Northeastern region, some methodological differences, such as the inclusion of all stroke subtypes and of recurrent events, particularly in the Fortaleza study, make comparisons more difficult. Our high 28-day case-fatality rate for hemorrhagic stroke found in João Pessoa (24.3\%) also located in the Northeastern region might be due to under-notification of mild events. Because the hospital in this city is the only one among the three studied that has a neurosurgery service, it is likely to admit more severe cases. Moreover, the small sample in this center could introduce some kind of bias into the analysis.

Most early case-fatality risk factors for hemorrhagic and ischemic stroke are well-described in the literature ${ }^{6,12}$. Overall, we found that advanced age, diabetes and previous heart disease were associated with a high case-fatality rate at 28 days for the ischemic subtype. However, we were not able to show any statistical differences in the distribution of risk factors according to stroke subtypes among the centers.

Even considering the methodological differences related to population-based or hospital-based studies, we found a trend of relatively low early death rates due to stroke, particularly in São Paulo and Natal. Moreover, the low early casefatality rates found in more developed regions in Brazil might explain the hypothesis of high mortality due to high incidence rates ${ }^{13}$ rather than high lethality ${ }^{6}$.

Our study had some limitations. We only investigated stroke cases among people aged 35 years or over. The number of stroke cases in João Pessoa at 10 days of follow-up was very small, which may have introduced some kind of bias into the analysis. However, it is important to note that regarding the data from stroke cases in João Pessoa, the differences in the case-fatality rate were not statistically significant. In addition, we only included data from three cities in Brazil. Contrasting with this, the present study has some strength because it is the first paper to compare case-fatality rates among hospitals located in different cities in Brazil.

In conclusion, despite the sociodemographic and modifiable risk factor differences observed in our study sample, we did

Table 2.10- and 28-day case-fatality age-adjusted* rates according to study location and stroke subtype.

\begin{tabular}{|c|c|c|c|c|c|c|}
\hline \multicolumn{7}{|l|}{ 10-day } \\
\hline \multirow{2}{*}{ Place } & \multicolumn{2}{|c|}{ Ischemic } & \multicolumn{2}{|c|}{ Hemorrhagic } & \multicolumn{2}{|c|}{ All } \\
\hline & Death & Rate $(95 \% \mathrm{Cl})$ & Death & Rate $(95 \% \mathrm{Cl})$ & Death & Rate $(95 \% \mathrm{Cl})$ \\
\hline João Pessoa & 5 & $14.1(2.2-26.0)$ & 1 & $6.0(-7.4-19.4)$ & 6 & $13.4(3.4-23.3)$ \\
\hline Natal & 12 & $4.9(2.2-7.6)$ & 3 & $8.8(0.2-17.5)$ & 15 & $5.4(2.8-8.0)$ \\
\hline São Paulo & 40 & $7.5(5.3-9.8)$ & 15 & $14.4(7.7-21.1)$ & 55 & $8.7(6.5-10.9)$ \\
\hline Total & 57 & $7.0(5.3-8.8)$ & 19 & $12.3(7.2-17.4)$ & 76 & $7.9(6.2-9.7)$ \\
\hline \multicolumn{7}{|l|}{ 28-day } \\
\hline \multirow{2}{*}{ Place } & \multicolumn{2}{|c|}{ Ischemic } & \multicolumn{2}{|c|}{ Hemorrhagic } & \multicolumn{2}{|c|}{ All } \\
\hline & Death & Rate $(95 \% \mathrm{Cl})$ & Death & Rate $(95 \% \mathrm{Cl})$ & Death & Rate $(95 \% \mathrm{Cl})$ \\
\hline João Pessoa & 7 & $19.8(6.2-33.4)$ & 4 & $24.9(0.4-49.3)$ & 11 & $24.3(11.8-36.8)$ \\
\hline Natal & 20 & $8.2(4.8-11.7)$ & 3 & $8.8(0.2-17.5)$ & 23 & $8.4(5.2-11.6)$ \\
\hline São Paulo & 63 & $11.9(9.1-14.7)$ & 22 & $22.4(14.4-30.3)$ & 85 & $13.5(10.8-16.2)$ \\
\hline Total & 90 & $11.1(8.9-13.3)$ & 29 & $19.8(13.6-26.0)$ & 119 & $12.5(10.4-14.5)$ \\
\hline
\end{tabular}

*Age-adjusted according to the population of São Paulo. 
not find any substantial differences in early case-fatality rates according to stroke subtypes, when comparing three cities in Brazil. Overall, we found higher hemorrhagic stroke case-fatality rates than ischemic ones up to 28 days. Population-based studies with larger sample sizes, including different ethnic groups, should be conducted to further confirm these results.

\section{References}

1. Lotufo PA, Goulart AC, Fernandes TG, Bensenor IM. A reappraisal of stroke mortality trends in Brazil (1979-2009). Int J Stroke 2012 (in press).

2. Lotufo PA. Stroke in Brazil: a neglected disease. São Paulo Med J 2005;123:3-4.

3. Lotufo PA, Bensenor IM. Stroke mortality in Brazil: one example of delayed epidemiological cardiovascular transition. Int J Stroke 2009;4:40-41.

4. Cabral NL, Goncalves AR, Longo AL, et al. Incidence of stroke subtypes, prognosis and prevalence of risk factors in Joinville, Brazil: a 2 year community based study.J Neurol Neurosurg Psychiatry 2009;80:755-761.

5. Minelli C, Fen LF, Minelli DP. Stroke incidence, prognosis, 30-day, and 1-year case fatality rates in Matao, Brazil: a population-based prospective study. Stroke 2007;38:2906-2911.

6. Goulart AC, Bensenor IM, Fernandes TG, Alencar AP, Fedeli LM, Lotufo PA. Early and one-year stroke case fatality in Sao Paulo, Brazil: applying the World Health Organization's Stroke STEPS. J Stroke Cerebrovasc Dis 2011 (in press).

7. Martins Jr AN Jr., Figueiredo MM, Rocha OD, Fernandes MA, Jeronimo SM, Dourado Jr ME. Frequency of stroke types at an emergency hospital in Natal, Brazil. Arq Neuropsiquiatr 2007;65:1139-1143.
8. de Carvalho JJ, Alves MB, Viana GA, et al. Stroke epidemiology, patterns of management, and outcomes in Fortaleza, Brazil: a hospital-based multicenter prospective study. Stroke 2011;42:33413346.

9. Bonita R, Mendis S, Truelsen T, Bogousslavsky J, Toole J, Yatsu F. The global stroke initiative. Lancet Neurol 2004;3:391-393.

10. Goulart AC, Bustos IR, Abe IM, et al. A stepwise approach to stroke surveillance in Brazil: the EMMA (Estudo de Mortalidade e Morbidade do Acidente Vascular Cerebral) study. Int J Stroke 2010;5:284-289.

11. Feigin VL, Lawes CM, Bennett DA, Barker-Collo SL, Parag V. Worldwide stroke incidence and early case fatality reported in 56 population-based studies: a systematic review. Lancet Neurol 2009;8:355-369.

12. Eriksson SE, Olsson JE. Survival and recurrent strokes in patients with different subtypes of stroke: a fourteen-year follow-up study. Cerebrovasc Dis 2001;12:171-180.

13. O’Donnell MJ, Xavier D, Liu L, et al. Risk factors for ischaemic and intracerebral haemorrhagic stroke in 22 countries (the INTERSTROKE study): a case-control study. Lancet 2010;376:112-123. 